\title{
Effect of Cenosphere Fly Ash on the Thermal, Mechanical, and Morphological Properties of Rigid PVC Foam Composites
}

\author{
Parisa Khoshnoud and Nidal Abu-Zahra*
}

\author{
Department of Materials Science and Engineering, University of Wisconsin-Milwaukee, 3200 North Cramer \\ Street, Milwaukee, WI 53201, USA
}

\begin{abstract}
Cenosphere fly ash is a byproduct of coal combustion processes of power plants. It is composed of hollow, hard shelled, minute spheres, which are made up of silica, iron, and alumina. In this study, cenosphere fly ash is incorporated into rigid PVC foam to improve thermal and mechanical properties of their composites. Microstructural, physical, mechanical, and thermal properties of rigid PVC foam extruded with different loadings of cenosphere fly ash (6, 12, 18phr) are characterized. The measured density of the extruded PVC foam composites increased with cenosphere content, indicating a hindrance to the foaming process. Tensile and flexural mechanical properties improved at higher cenosphere content, while the impact strength decreased at initial loading of $6 \mathrm{phr}$ of cenosphere particles and remained steady at higher loadings. Thermal characterization of the extruded samples showed that glass transition temperature remained almost unaffected, while TGA analysis revealed no change in the initial degradation temperature and significant improvement in the final degradation temperature. Thermo-mechanical properties measured by DMA revealed a remarkable improvement in the viscoelastic properties of the composites reinforced with cenosphere particles. SEM analysis of the composites microstructure confirmed that the cenosphere particles were mechanically interlocked with good interfacial interaction in the PVC matrix.
\end{abstract}

Keywords: Polyvinyl Chloride Foam, Fly ash, Characterization, Tensile, Flexural, DMA, SEM, XRD, TGA, DSC.

\section{INTRODUCTION}

Cenospheres, a byproduct of coal burning process in power plants, are a hollow type of fly ash composed of hard shelled minute spheres made up of silica, iron, and alumina [1]. Its size ranges from 1 to 500 microns and it has a density ranging from 0.4 to 0.8 $\mathrm{g} / \mathrm{cm}^{3}$ [2]. Cenospheres are widely used as reinforcing fillers in polymers and ceramics due to their unique properties; such as, low density, low thermal conductivity, low water absorption, high particle strength, low cost, and a unique smooth spherical surface [3, 4]. Consequently, using cenospheres as a filler in plastic and rubber composites contributes to weight reduction, shrinkage and warpage reduction, improved surface texture, and higher resistance to water absorption $[5,6]$.

Polymer composites are broadly used in manufacturing due to their enhanced properties; such as strength to weight ratio and ease of fabrication [7, 8]. The use of cenospheres in polymer composites has been investigated by a number of researchers. Kadam et al. [4] reported that the tensile properties and crystallinity in epoxy/cenosphere composites decrease, whereas flexural properties, thermal properties, and electrical stability increase, with increasing the cenospheres concentration. The morphological

*Address correspondence to this author at the Department of Materials Science and Engineering, University of Wisconsin-Milwaukee, 3200 North Cramer Street, Milwaukee, WI 53201, USA; Tel: +1-414-241-1777;

E-mail:nidal@uwm.edu properties studied by SEM showed uniform dispersion of the cenosphere particles. Deepthi et al. [9] studied high density polyethylene (HDPE)/cenosphere composites using maleate ester modified HPDE; they reported improvement in mechanical and thermal properties and a decrease in crystallinity. Jena et al. [10] prepared laminated bamboo-fiber epoxy composite filled with cenospheres using conventional hand layup technique; they reported that the impact properties of the composites were greatly enhanced by the addition of cenosphere particles and the maximum impact strength was realized at $1.5 \mathrm{wt} \%$ cenospheres.

Das et al. [6] investigated the structural, thermal, mechanical, and dynamic mechanical properties of polypropylene (PP)/cenosphere composites. They reported uniform dispersion and distribution of cenosphere particles in PP matrix and an improvement in the dynamic mechanical and tensile properties of the composites. However, the impact strength and crystallinity of the composites decreased with increasing cenosphere content. Labella et al. [7] prepared cenosphere/vinyl ester syntactic foams to study their mechanical and thermal properties. They reported that the flexural modulus increased by $47 \%$ at 60 vol.\% cenosphere loading, while the flexural strength and coefficient of thermal expansion (CTE) decreased by $73 \%$ and $48 \%$, respectively. Similarly, Qiao et al. [11] showed that the dynamic mechanical properties were enhanced in Polyurea/cenosphere composites. 
The effect of cenosphere concentration on the mechanical, thermal, rheological, and morphological properties of Nylon6 was studied by Wasekar et al. [12]; they reported an improvement in the elongation at break, impact, and flexural strengths by the addition of a small amount of cenospheres. Rohatgi et al. [13] reported an increase in the compression modulus of polyester/cenosphere composites with increasing the cenospheres content. Kulkarni et al. [14] studied the effect of cenosphere particle size (100-300 mesh) on the properties of acrylonitrile butadiene styrene-filled composites. Their results showed that smaller particles yield better thermal, electrical, and mechanical properties. Manjunath et al. [15] reported that the glass transition temperature $(\mathrm{Tg})$, activation energy for decomposition, and Smoke Density Rating (SDR) of $\mathrm{PVC} /$ cenosphere composites decrease with increasing the cenosphere content without affecting their Limiting Oxygen Index (LOI) and thermal stability. Roy et al. [16] added amino silane functionalized cenospheres to poly(vinyl butyral) using melt mixing method; they reported that the dielectric properties of the composite films is dependent on the cenosphere content.

Recently, researchers focused on studying the tribological properties of cenosphere filled polymer composites. Thakur et al. [17] studied the mechanical and tribological behavior of cenosphere/vinyl ester composites using Taguchi technique. They prepared composites with three different size cenosphere particles and their results showed that the submicron sized particles improved significantly the mechanical properties and wear resistance of the composites. Chand et al. [18] studied abrasive wear behavior of low density polyethylene (LDPE)/silane treated cenosphere composites; they reported a maximum wear resistance of $10-11 \mathrm{~m}^{3} / \mathrm{N} \cdot \mathrm{min}$, a composite containing $10 \mathrm{wt} \%$ silane treated cenospheres. Chand et al. [19] also prepared HDPE/silane treated cenosphere composites and reported significant improvement in the impact strength and wear resistance of the composites. Sharma et al. [20] prepared LDPE/cenosphere composites with inhomogeneous dispersions of cenospheres and reported that the dielectric constant decreases with increasing cenosphere content with a Maxwell-Garnet approximation. Chauhan et al. [21] prepared vinyl ester composites containing micron sized cenospheres and reported a significant improvement in wear resistance in the presence of cenospheres.

However, very few researchers investigated the use of fly ash in polymer foams. Usta [22] investigated the flame retardancy behavior of rigid polyurethane (PU) foams containing fly ash using a cone calorimeter. It was reported that the incorporation of fly ash particles in PU foam dramatically increased the fire resistance and thermal stability of the composite foams. Choew et al. [23] reported the usage of PU foam/fly ash blends as a commercial product to encapsulate heavy metals. It was observed that PU foam/fly ash blends were waterproof, with good resistance to heat and light. The blends contained a maximum of $18 \%$ fly ash in their composition. Gupta et al. [24] focused on the effects of cenosphere fly ash radius ratio on compressive properties of syntactic foams. Their results showed that compressive strength and modulus depends on the internal radius of the particles and these properties are higher in those specimens filled with smaller internal radius cenospheres.

Rigid Polyvinyl Chloride (PVC) foam composites are one of the most common materials used in building industry in the form of profiles, sheets, and pipes due to their low cost, low density, low thermal conductivity, improved acoustic damping properties, and good fire retardancy [25-27]. In our previous work [28], physical, mechanical, thermal, and microstructural properties of PVC foam composites reinforced with two different types of precipitator fly ash, class $C$ and class $F$, were studied and compared. Based on our research so far, there is no work noted of using cenosphere as a filler in PVC foams. In this study, cenosphere fly ash was loaded as 6phr, 12phr, and 18phr in PVC foam matrix. The effects of adding cenosphere to the matrix phase and its content on thermal, mechanical, and microstructural properties of rigid PVC foams were investigated.

\section{EXPERIMENTAL}

\subsection{Materials}

Rigid PVC resin was acquired from Shintech, USA. It has an inherent viscosity of 0.74 (ASTM D1243); bulk density of $0.58 \mathrm{~g} / \mathrm{cm}^{3}$ (ASTM D 1895), and maximum volatiles of $0.12 \%$ (ASTM D3030). A commercially available thermal stabilizer, Thermolite T-137, and processing aids, PLASTISTRENGTH P530 and P770, were acquired from Arkema, USA. Other ingredients used in preparing the test samples are: Lubricants LOXIOL 2986 and LOXIOL 2987 produced by Oleochemicals; paraffin wax Petrac 215 produced by Ferro Corp.; Calcium Stearate COAD 10 produced by Norac Corp.; chemical blowing agents azodicarbonamide (ADC) produced by Season Corp.; 
Table 1: PVC Foam Composites Formulation

\begin{tabular}{|c|c|c|c|c|}
\hline Raw Materials (phr) & Pure & TG6 & TG12 & TG18 \\
\hline \hline PVC resin & 100 & 100 & 100 & 100 \\
\hline TG-cenosphere & 0 & 6 & 12 & 18 \\
\hline
\end{tabular}

and Sodium Hydrogen Carbonate (FICEL SBH) produced by Hughes Polymer Additives Corporation. TG type cenosphere fly ash was acquired from Sphere One Inc., USA.

\subsection{Preparation of PVC/Cenosphere Foam}

PVC foam compounds were prepared using a high shear mixer (Gunther Pepenmeier, Machinen-u. Detmoid, Type: TSHK). The stabilizer was added at $52^{\circ} \mathrm{C}$, cenospheres and processing aids were added to the PVC resin at $52^{\circ} \mathrm{C}$ and $58^{\circ} \mathrm{C}$, respectively. Finally, the lubricants and the blowing agents were added at $66^{\circ} \mathrm{C}$. PVC foam compounds containing $0,6,12$, and $18 \mathrm{phr}$ cenosphere were extruded by using a $3.175 \mathrm{~cm}$, 20:1 (L/D) single screw extruder (Themoplas New England Wire Machinery Co. Inc.) at a screw speed of $60 \mathrm{rpm}$. The extrusion temperature profile used for mixing was in the range of 158 to $175^{\circ} \mathrm{C}$. The compound formulations and sample codes are listed in Table 1. The sample without cenosphere is called pure and the other samples are named based on TG type cenosphere content.

\subsection{Sample Characterization}

\subsubsection{Physical Properties}

The experimental density $(\rho)$ was calculated according to ASTM D272 by weighting and measuring the volume of the composites.

\subsubsection{Mechanical Properties}

Tensile properties were determined using an Instron 3365 universal testing machine on rectangular specimens measuring $30.48 \times 2.54 \times 0.67 \mathrm{~cm}$ at a crosshead speed of $0.021 \mathrm{~cm} / \mathrm{s}$. Flexural properties were determined using Instron 3365 with a three-point bending test set-up on rectangular specimens measuring $20.32 \times 2.54 \times 0.67 \mathrm{~cm}$ at a crosshead speed of $0.021 \mathrm{~cm} / \mathrm{s}$. The span length was kept at $10.16 \mathrm{~cm}$. The flexural stress and strains were calculated using:

$$
\begin{gathered}
\sigma_{f}=\frac{3 P L}{2 b d^{2}} \\
\varepsilon_{f}=\frac{6 D d}{L^{2}}
\end{gathered}
$$

Where, $\sigma_{f}$ and $\varepsilon_{f}$ are flexural stress and strain on the outer surface at the midpoint; respectively, and $\mathrm{P}$, $L, b, d, D$ are the load, span length, specimen width, specimen thickness and midpoint deflection, respectively. The flexural strength was determined using the maximum stress value recorded before sample fracture and flexural modulus was determined by the slope of the initial linear region of the stressstrain curve.

Charpy impact properties were determined using TINIUS OLSEN impact tester machine (model IT 504) according to ASTM D 6110.

\subsubsection{Thermal Characterization}

Thermal properties of the foam composites were analyzed using: (1) Thermogravimetric analysis (TGA) using TA Instruments SDT 2960 in a temperature range of $25^{\circ} \mathrm{C}$ to $800^{\circ} \mathrm{C}$ at a heating rate of $10^{\circ} \mathrm{C} / \mathrm{min}$ under argon atmosphere; and (2) Differential Scanning Calorimetry (DSC) analysis using TA Instruments Q2000 analyzer. Foam composite samples weighing 5 to $10 \mathrm{mg}$ were heated in standard aluminum pans in a temperature range of $25^{\circ} \mathrm{C}$ to $260^{\circ} \mathrm{C}$ at a heating rate of $10^{\circ} \mathrm{C} / \mathrm{min}$.

Dynamic Mechanical Analysis (DMA) was performed on TA Instrument Q800 to evaluate the viscoelastic properties (storage modulus, loss modulus, and $\tan \delta$ ) of composites in the solid state. A three-point bending mode was used at a test temperature range of 30 to $120^{\circ} \mathrm{C}$ at a constant heating rate of $3^{\circ} \mathrm{C} / \mathrm{min}$ and a frequency of dynamic force of $1 \mathrm{~Hz}$.

\subsubsection{X-Ray Diffraction Analysis (XRD)}

Elemental and chemical analysis of the cenosphere particles were determined using an X-ray diffractometer (Bruker D8 Discovery) with a $\mathrm{CuK}_{\alpha}$ radiation $(\lambda=1.54056 \AA)$ source. The samples were scanned with the time per step $1.5 \mathrm{~s}$ from $10^{\circ}$ to $70^{\circ}(2 \theta)$. Weight percentage $\left(X_{i}\right)$ of each crystal phase in cenosphere was calculating using:

$$
X_{i}=\frac{1}{1+\left[k_{i} / I_{i}\left(I_{j} / k_{j}+I_{k} / k_{k}\right)\right]}
$$

where, $\mathrm{K}=\mathrm{I} / \mathrm{lc}$ and $\mathrm{I}$ is intensity of largest peak in the phase. 


\subsection{Scanning Electron Microscopy and Energy Dispersive X-Ray Analysis (SEM/EDX)}

Topcon SM-300 SEM was used for imaging and microstructural analysis. The specimens were fractured in liquid nitrogen and coated using a sputter coater to minimize the charging effect and to improve the conductivity of the samples prior to analysis. SEM/EDX was also used to confirm the chemical composition of cenosphere.

\section{RESULTS AND DISCUSSION}

\subsection{Cenosphere Characterization}

The density of the cenosphere was measured to be $0.75 \mathrm{~g} / \mathrm{cm}^{3}$ with a particle size ranging from 5 to $500 \mu \mathrm{m}$. The SEM micrograph of cenosphere, shown in Figure 1, confirms a wide particle size distribution. The elemental and chemical compositions of cenosphere were characterized by SEM/EDX and XRD as shown in

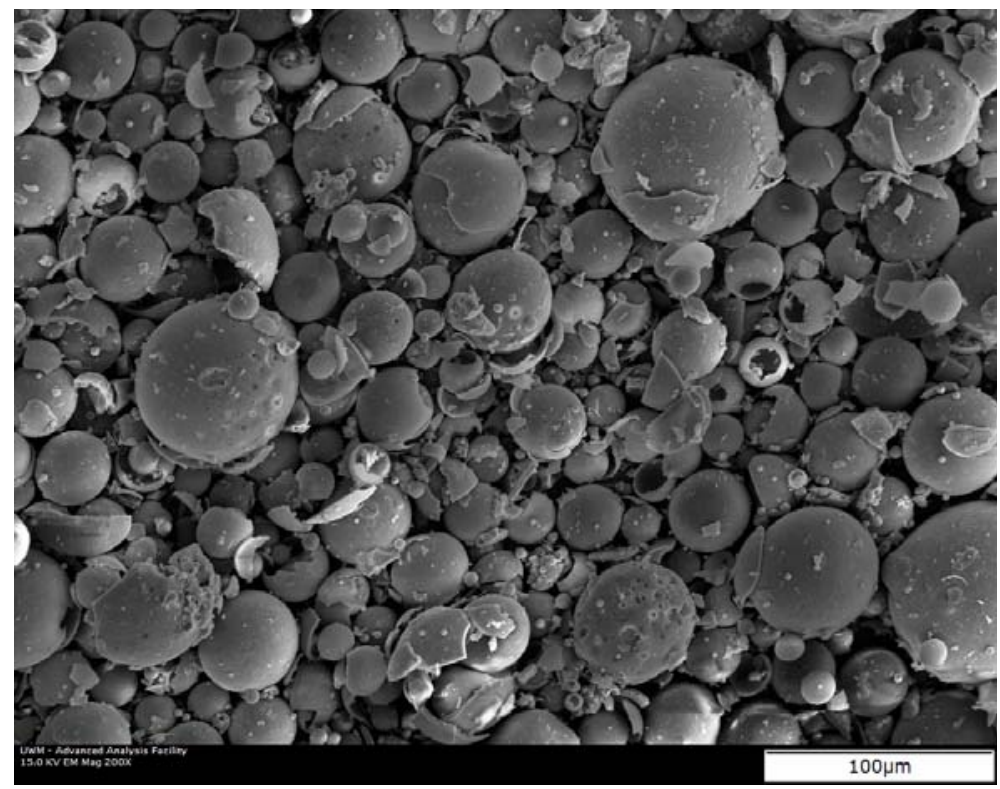

Figure 1: SEM micrograph of Cenospheres.

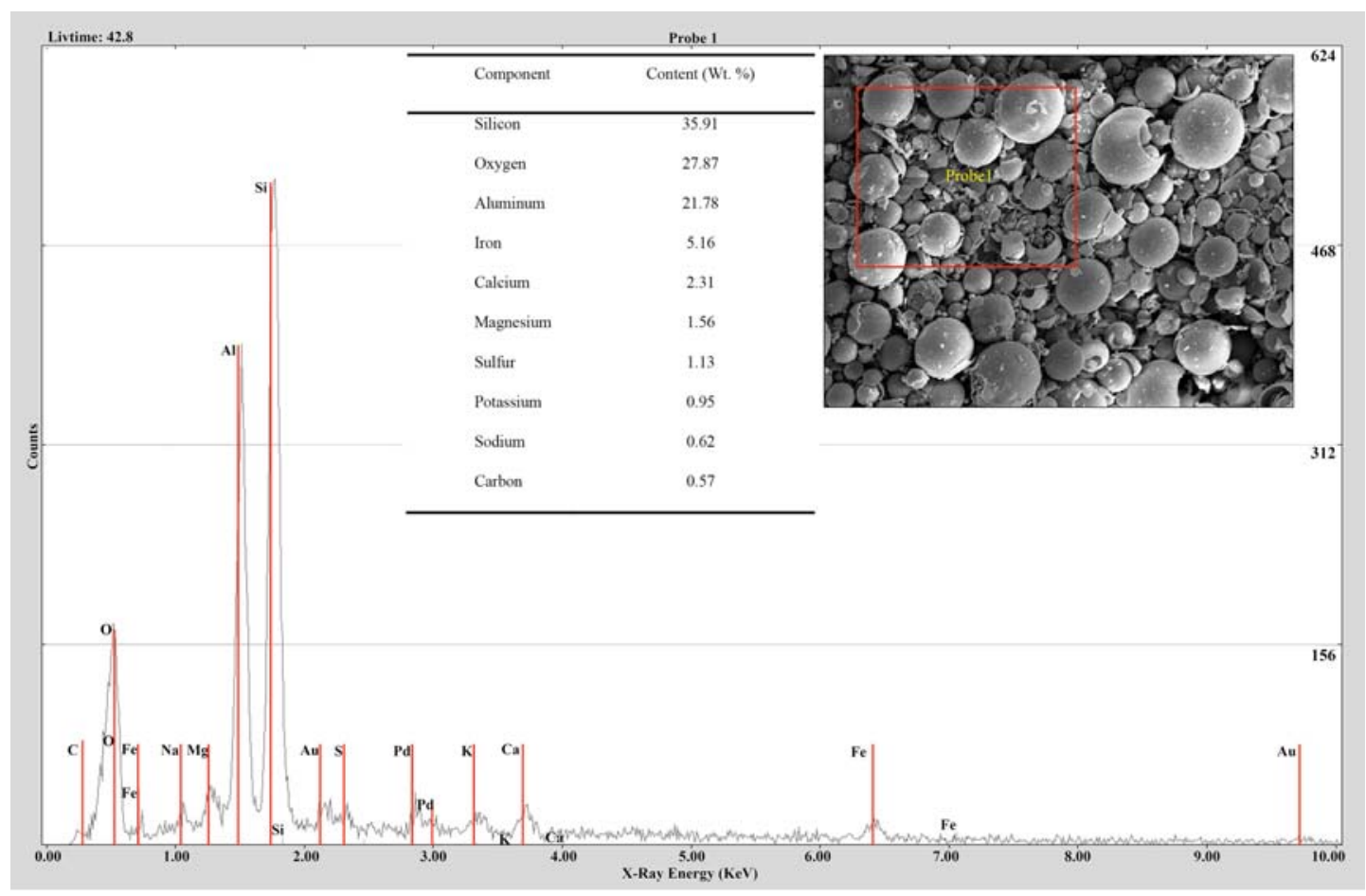

Figure 2: Elemental composition of cenosphere characterized by SEM/EDX. 


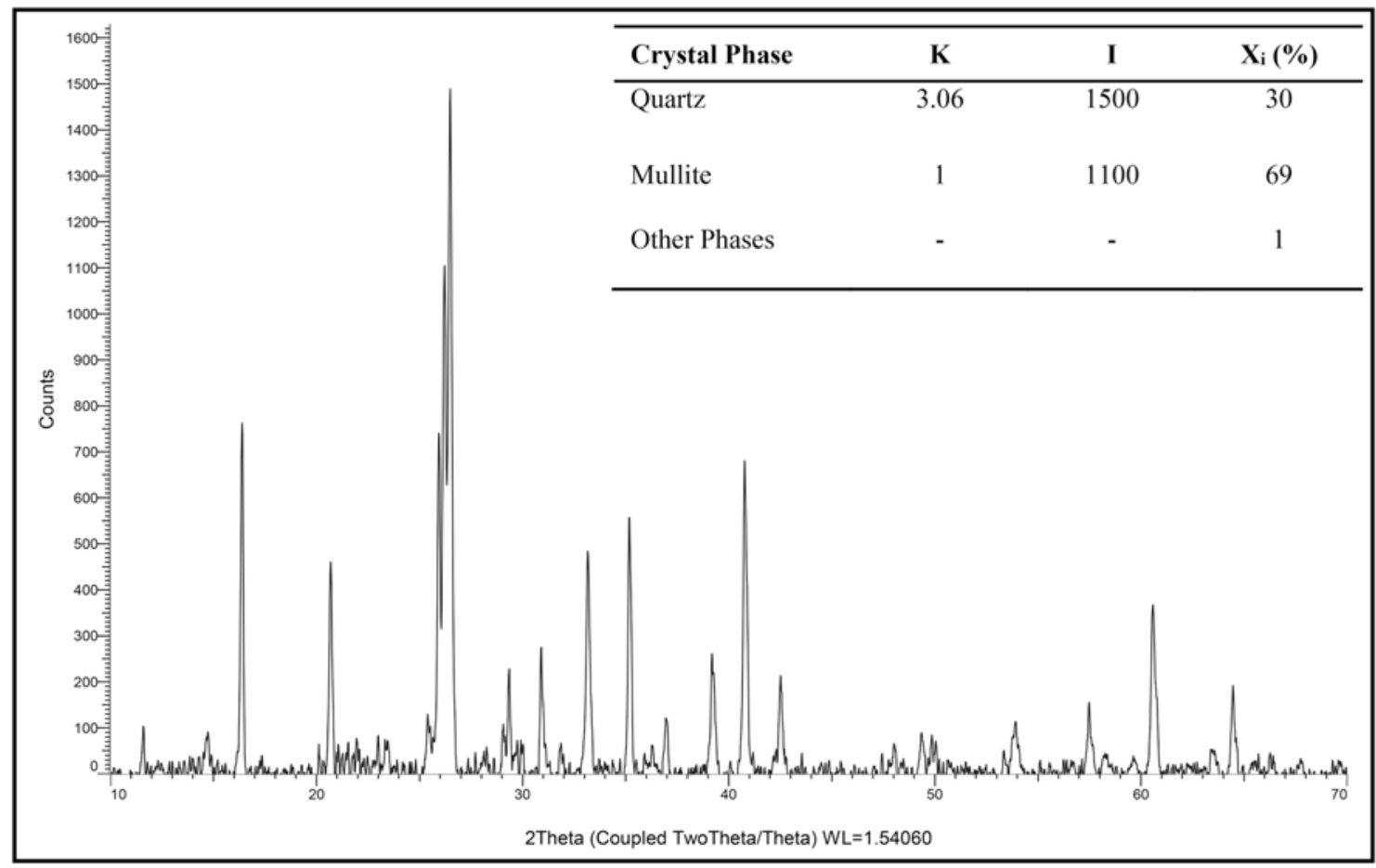

Figure 3: X-Ray diffraction spectrum and weight percentage of crystal phases of cenosphere.

Figures 2 and 3, respectively. XRD result shows that the cenospheres contain mainly Quartz and Mullite crystal phases. Weight percentage of each phase is calculated using Equation 3 and reported in Figure 3.

\subsection{PVC foam/Cenosphere Composite Characteri- zation}

\subsubsection{Physical Properties}

The measured density of the PVC foam composites are presented in Figure $\mathbf{4}$ and summarized in Table $\mathbf{2}$. The results show that the foam density increases by increasing the cenosphere content, indicating a denser composite microstructure with higher cenosphere loadings. By adding more filler, foaming process is hindered, thus resulting in smaller cells and denser matrix. This observation is consistent with the SEM images shown in Figure 12.

\subsubsection{Mechanical Properties}

The tensile strength and tensile modulus of the foam composites as a function of the cenosphere content are shown in Figures $\mathbf{5}$ and $\mathbf{6}$, respectively. It is

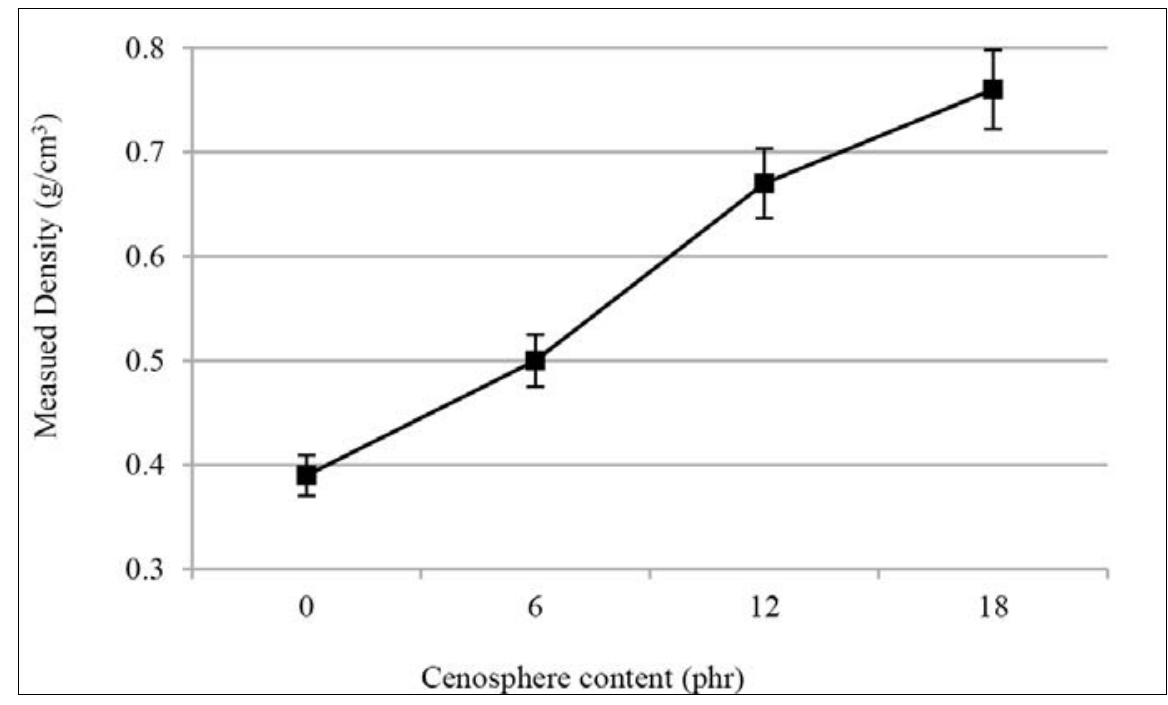

Figure 4: Measured Density of PVC foam composites vs. cenosphere content (phr). 
Table 2: Density of PVC Foam Composites

\begin{tabular}{|c|c|c|c|c|}
\hline Sample & Pure & TG6 & TG12 & TG18 \\
\hline \hline Measured Density $\left(\mathrm{g} / \mathrm{cm}^{3}\right)$ & 0.39 & 0.50 & 0.67 & 0.76 \\
\hline
\end{tabular}

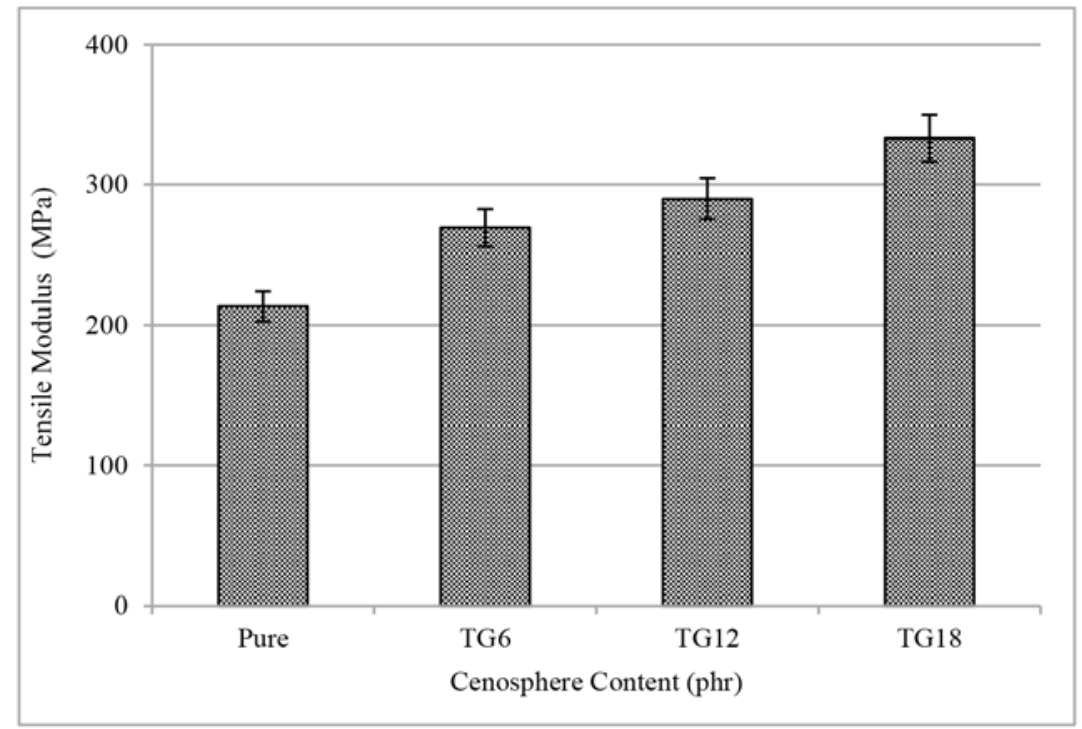

Figure 5: Tensile modulus of PVC/Cenosphere foam composites.

evident that the tensile strength increases as the filler content increases in the composites, an indication of high strength and bonding energy between the filler and the matrix $[6,17,28]$. Similarly, the incorporation of higher amounts of cenospheres in PVC foam, improves the elastic modulus of the composites [28]. The higher tensile strength and elastic modulus of the composites may also be due to the strong interphase interaction between the PVC membranes and the cenospheres, which reduces the stress concentration sites under tensile loading.

The effect of cenosphere content on the flexural strength and modulus of PVC foam composites are presented in Figures 7 and 8, respectively. The flexural modulus was found to increase $136 \%$ by adding $6 \mathrm{phr}$ cenospheres compared to pure samples, reaching up to $220 \%$ increase with $18 \mathrm{phr}$ cenosphere composites. The increase in flexural modulus indicates higher

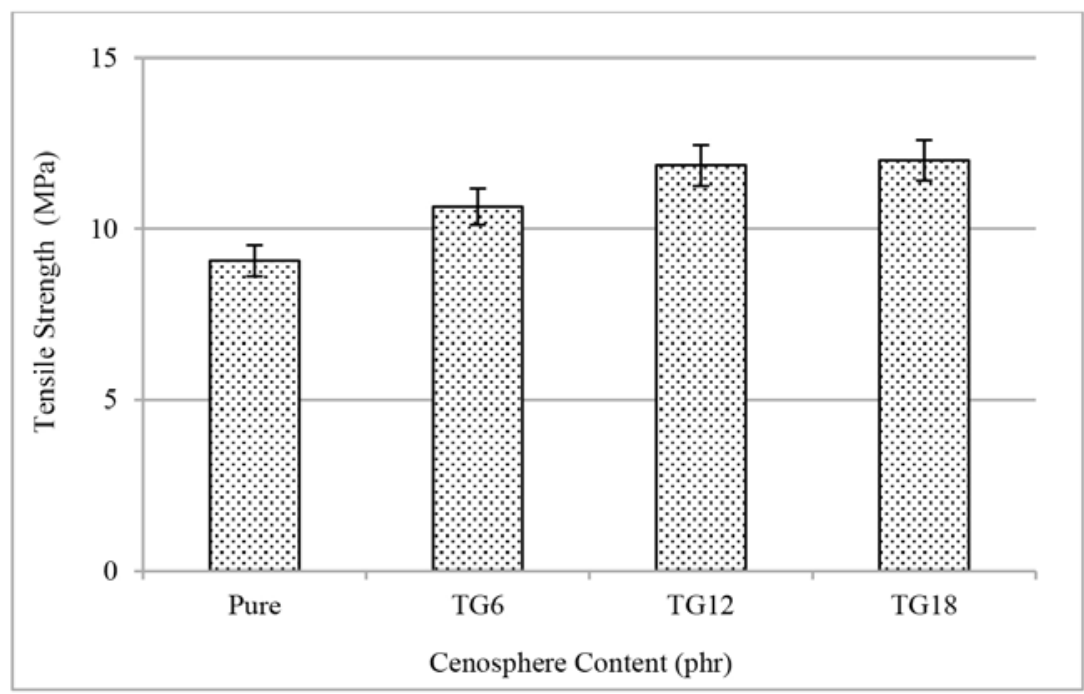

Figure 6: Tensile strength of PVC/Cenosphere foam composites. 


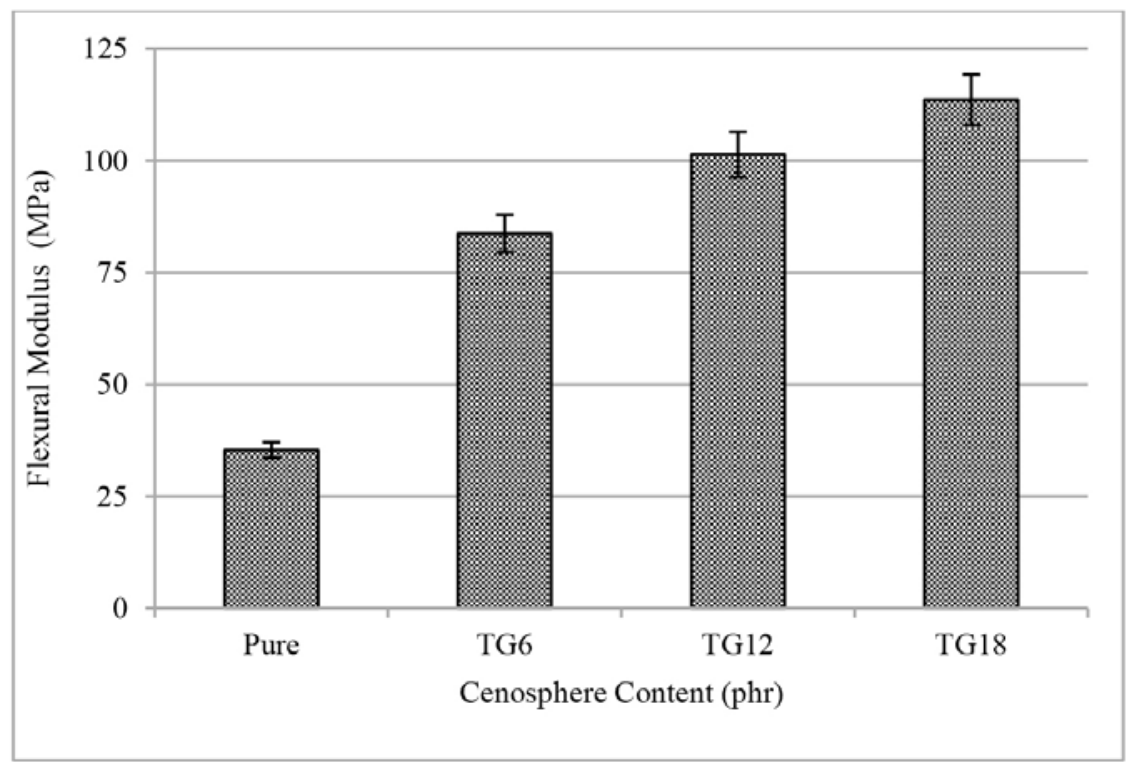

Figure 7: Flexural modulus of PVC/Cenosphere foam composites.

stiffness of the composites. Similarly, adding cenosphere particles to the PVC foam matrix increases flexural strength up to $24 \%$ in the samples with $18 \mathrm{phr}$ cenospheres. The increase in both the flexural strength and modulus in the presence of cenospheres indicates good interfacial interaction between the filler and the polymer matrix. Also, it indicates minimum aggregation of the cenosphere particles and good dispersion in the PVC matrix $[4,17,28]$.

The effect of cenospheres on the impact strength of the composites is shown in Figure 9. By adding 6phr cenosphere particles, the impact strength and impact energy decrease. This can be attributed to the formation of stress concentration sites as a result of the strong interfacial bonding between the cenosphere particles and the matrix [4]. On the other hand, due to the unique spherical shape of the cenospheres, the particles cannot transfer the applied load easily and it causes a decrease in the impact energy to break and impact strength [4]. By increasing the cenosphere content above 6phr, the impact energy and strength are almost steady or nearly unaffected, which indicates more efficient load transfer in the composites containing higher loading of cenosphere particles.

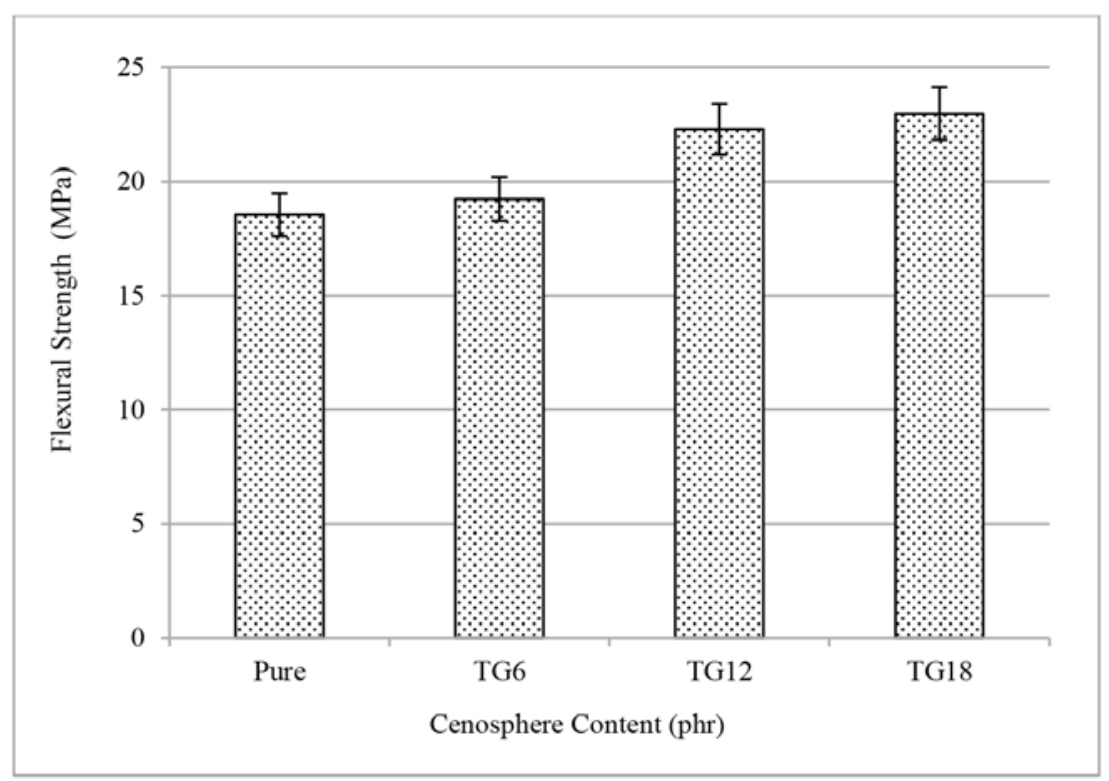

Figure 8: Flexural strength of PVC/Cenosphere foam composites. 


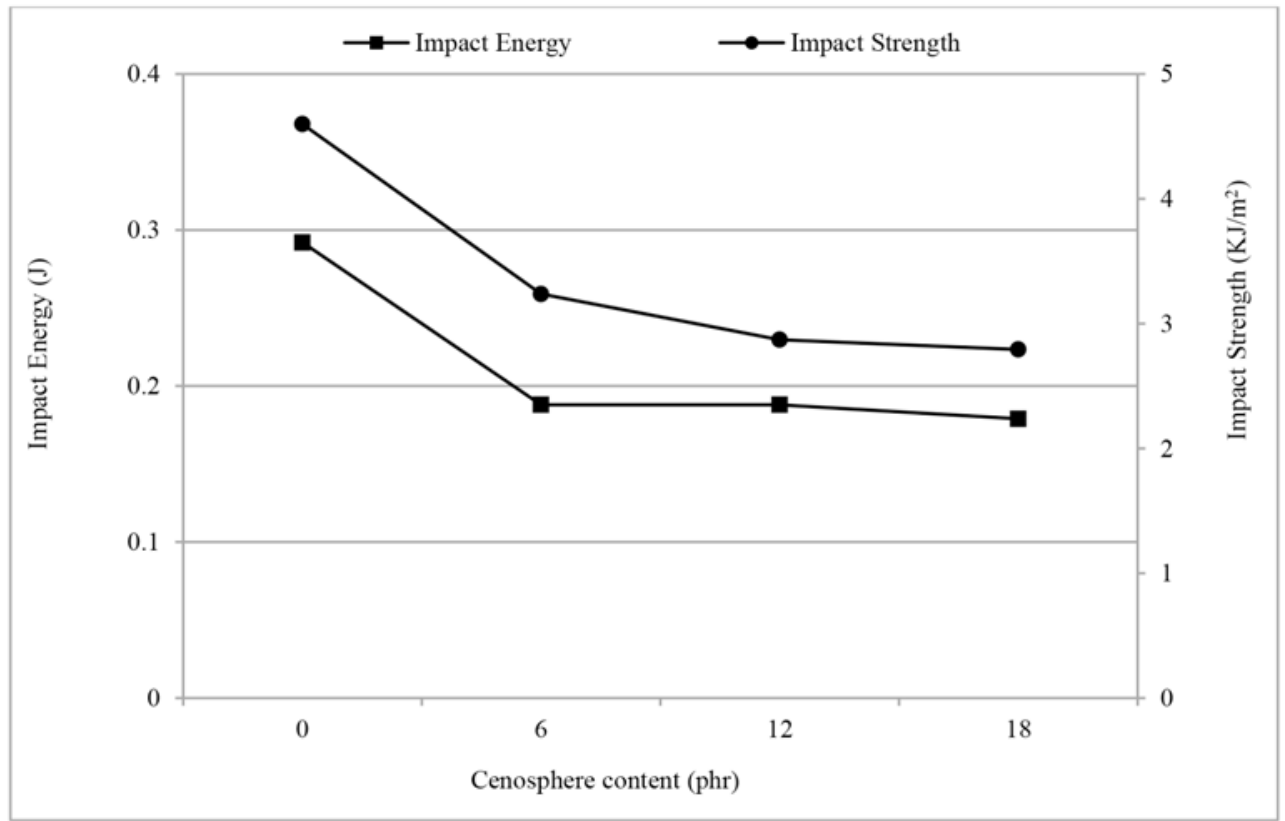

Figure 9: Impact strength and energy of PVC/Cenosphere foam composites.

Table 3: Summary of the Mechanical Properties of PVC/Cenosphere Foam Composites

\begin{tabular}{|c|c|c|c|c|c|c|}
\hline Sample & $\begin{array}{c}\text { Tensile Strength } \\
(\mathbf{M P a})\end{array}$ & $\begin{array}{c}\text { Tensile } \\
\text { Modulus (MPa) }\end{array}$ & $\begin{array}{c}\text { Flexural Strength } \\
(\mathbf{M P a})\end{array}$ & $\begin{array}{c}\text { Flexural Modulus } \\
(\mathbf{M P a})\end{array}$ & $\begin{array}{c}\text { Impact Energy } \\
(\mathbf{J})\end{array}$ & $\begin{array}{c}\text { Impact } \\
\text { Strength } \\
\left(\mathbf{K J} / \mathbf{m}^{2}\right)\end{array}$ \\
\hline \hline Pure & 9.06 & 213.35 & 18.54 & 35.358 & 0.29 \\
\hline TG6 & 10.65 & 269.37 & 19.23 & 83.69 & 0.188 \\
\hline TG12 & 11.85 & 290.04 & 22.28 & 101.33 & 0.188 \\
\hline TG18 & 12.00 & 333.18 & 22.98 & 113.59 & 2.64 \\
\hline
\end{tabular}

The mechanical properties of the PVC/cenosphere foam composites are summarized in Table 3.

\subsubsection{Thermal Properties}

The results from TGA analysis of the $\mathrm{PVC} /$ cenosphere foam composites are shown in Figure 10 and the degradation temperatures are summarized in Table 4. The pure samples show initial degradation temperature (IDT) and final degradation temperature (FDT) at $288.82^{\circ} \mathrm{C}$ and $428.76{ }^{\circ} \mathrm{C}$, respectively. TGA analysis shows insignificant change in IDT of the composites compared to pure samples i.e. $~ 3-5^{\circ} \mathrm{C}$, which is attributed to the separation of chlorine from the polymer chains [28, 29]. Enthalpy of IDT increases by adding cenospheres to PVC matrix and this increment in TG18 is about $23^{\circ} \mathrm{C}$, which is the maximum value. FDT is related to cracking of the hydrocarbon backbone, which is found to improve significantly in the case of cenosphere filled composites. It means that, in cenosphere filled samples more energy is required to break the hydrocarbon backbone indicating some bonding between the filler and the matrix.
A comparison between the final degradation enthalpies shows that the enthalpy of polymer backbone breaking increases with increasing the cenosphere content. It shows a maximum value in TG18, which is almost $350 \%$ improvement compared to the pure samples. Cenosphere is a ceramic material and has hollow shaped structure; therefore, by increasing the cenospheres content, the void portion of the cenospheres increases and the thermal conductivity decreases, and consequently the degradation temperature increases [4].

The residual weight in thermal degradation is the undecomposed inorganic filler and ash [29]. Residual weight at $800^{\circ} \mathrm{C}$ is found to be $17.95 \%$ in pure samples indicating that the ash of the PVC compound and the residual weight in TG6 containing $6 \mathrm{phr}$ cenosphere is $18.97 \%$ which is only $5.68 \%$ higher than pure sample. This factor increases with increasing the cenosphere content up to $27.13 \%$ in TG18 which has the highest amount of cenosphere loading. 


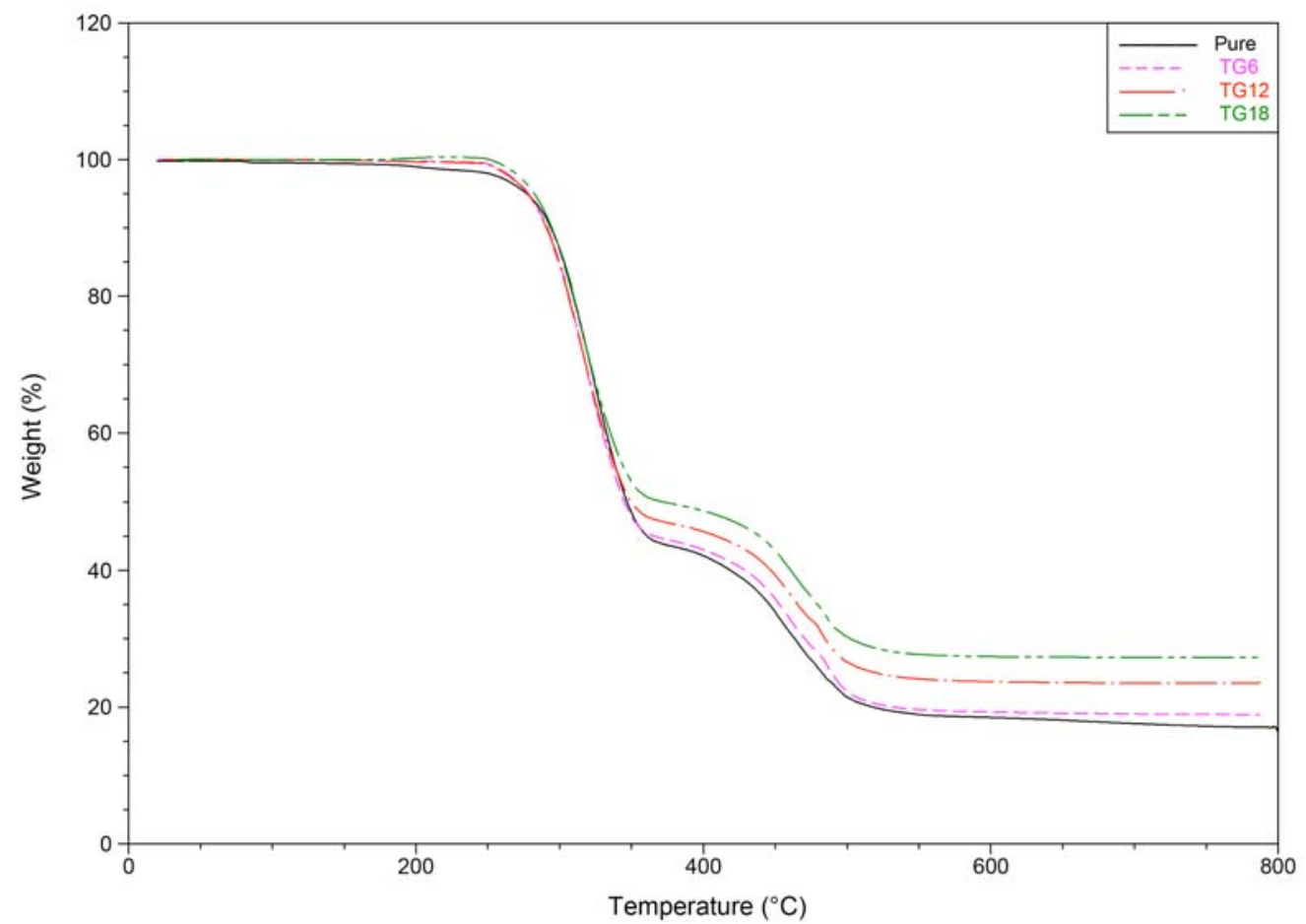

Figure 10: TGA curves of PVC/Cenosphere foam composites.

Table 4: Thermogravimetric Analysis (TGA) of Foam Specimens

\begin{tabular}{|c|c|c|c|c|c|}
\hline Sample & IDT $^{\text {a }}\left({ }^{\circ} \mathbf{C}\right)$ & Enthalpy of IDT $(\mathbf{J} / \mathbf{g})$ & FDT $^{\text {b }}\left({ }^{\circ} \mathbf{C}\right)$ & Enthalpy of FDT $(\mathbf{J} / \mathbf{g})$ & $\begin{array}{c}\% R e s i d u a l ~ W e i g h t \\
\text { at } 800{ }^{\circ} \mathbf{C}\end{array}$ \\
\hline \hline Pure & 288.82 & 110.6 & 440.70 & 9.74 & 17.95 \\
\hline TG6 & 284.55 & 128.3 & 451.85 & 17.35 & 23.97 \\
\hline TG12 & 283.50 & 125.1 & 453.77 & 27.63 & 23.4 \\
\hline TG18 & 285.09 & 143.8 & 457.18 & 43.99 & 27.13 \\
\hline
\end{tabular}

${ }^{a}$ IDT: Initial Degradation Temperature $;{ }^{b}$ FDT: Final Degradation Temperature.

Figure 11 shows DSC thermograms of $\mathrm{PVC} /$ cenosphere foam composites. Glass transition temperature $\left(T_{g}\right)$ and percentage of gelation of the PVC foam composites do not seem to change significantly with the incorporation of cenospheres in the composites. This behavior was also observed in our previous work [28]. PVC/natural filler and PVC/Carbon fiber composite systems reported by lulianelli et al. [30] and Rathy et al. [31], respectively. The degree of gelation, initial $\left(\mathrm{Tg}_{\mathrm{i}}\right)$, middle $\left(\mathrm{Tg}_{\mathrm{m}}\right)$, and final $\mathrm{T}_{\mathrm{g}}\left(\mathrm{Tg}_{\mathrm{f}}\right)$ values are reported in Table 5.

The viscoelastic properties of the PVC/cenosphere composites were determined by DMA analysis. These are reported in terms of variations of storage modulus (E'), which represents the elastic nature and loss modulus ( $E ")$, which represents the viscous nature, as a function of temperature. E' and E" are presented in Figures $\mathbf{1 2 a}$ and $\mathbf{1 2 b}$, respectively. The magnitude of $E^{\prime}$ seems to increase significantly with the incorporation of cenospheres. This increase indicates an improvement of the stiffness in accordance with the expectations of the common behavior of composites filled with rigid spherical particles [6]. The extent of increase of storage modulus in TG18 at $50^{\circ} \mathrm{C}$ is approximately $180 \%$ compared to pure samples.

The peak intensity of loss modulus is found to increase with the addition of small amounts of cenospheres (6phr) to PVC foam. This phenomenon may be due to the enhancement in the energy dissipation ability as a result of the presence of spherical filler in the composites and also an increase in the polymer-filler and filler-filler slippage at $\operatorname{Tg}[11$, 28]. $\mathrm{Tg}$ of the PVC/cenosphere foam composites was measured in two different ways; as the temperature at the peak of the loss modulus and as the temperature at the maximum of tand at about $1 \mathrm{~Hz}$ frequency. Both 


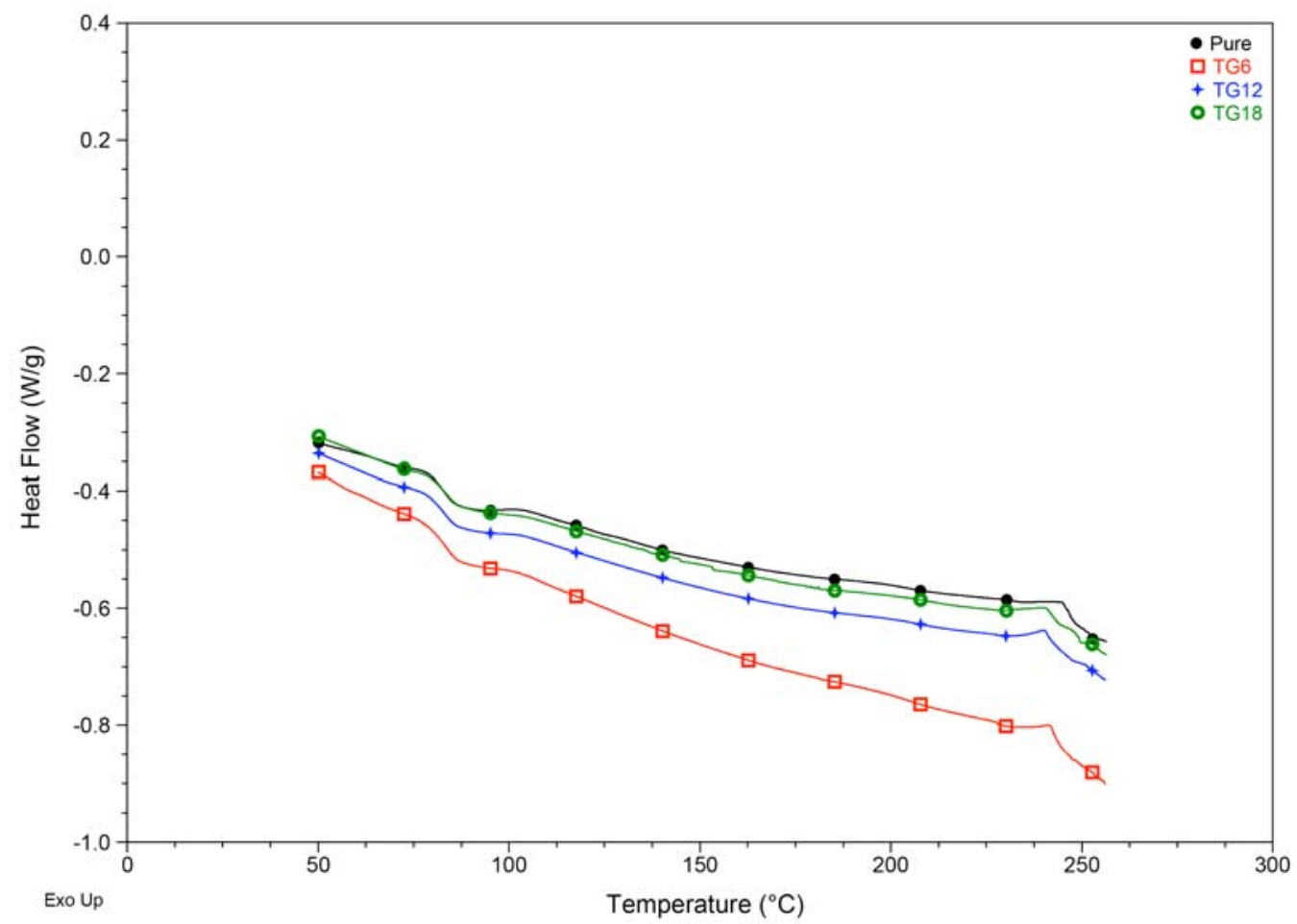

Figure 11: DSC curves of PVC/Cenosphere foam composites.

Table 5: DSC Analysis of PVC/Cenosphere Foam Composites

\begin{tabular}{|c|c|c|c|c|}
\hline Sample & $\begin{array}{c}\mathbf{T g}_{\mathrm{i}} \\
\left({ }^{\circ} \mathbf{C}\right)\end{array}$ & $\begin{array}{c}\mathbf{T g}_{\mathrm{m}} \\
\left({ }^{\circ} \mathbf{C}\right)\end{array}$ & $\begin{array}{c}\mathbf{T g}_{\mathrm{f}} \\
\left({ }^{\circ} \mathbf{C}\right)\end{array}$ & $\begin{array}{c}\text { Gelation } \\
(\%)\end{array}$ \\
\hline \hline Pure & 79.17 & 82.55 & 86.81 & $85.79 \%$ \\
\hline TG6 & 78.71 & 83.61 & 86.33 & $77.43 \%$ \\
\hline TG12 & 78.97 & 82.69 & 86.78 & $78.03 \%$ \\
\hline TG18 & 80.02 & 83.45 & 86.91 & $82.17 \%$ \\
\hline
\end{tabular}

values, reported in Table 6, are almost constant up to $12 \mathrm{phr}$ cenosphere loading; however it increases $1^{\circ} \mathrm{C}$ in TG18, which may be due to the segmental immobilization of the filler surface [11].

\subsubsection{Microstructural Properties}

The interfacial interaction between the cenosphere particles and the foam matrix walls, as well as the state of dispersion and distribution of the cenospheres at the microstructural level were investigated by SEM. Figure 13 shows the SEM images of PVC foam composites with different loadings of cenosphere particles. The difference in cenosphere loading in the samples between 6 to $18 \mathrm{phr}$ is visible in figures (a) to (c), ata constant magnification of $200 x$, indicating a good distribution of the cenospheres in the foam matrix [6]. In addition, it is evident in figures (a)-(c) that the foam cell size decreases with increasing the cenosphere content due to the higher restriction to the foaming process.

At a higher magnification of $1000 x$, figures $(d)$ to $(f)$ show the presence of tightly embedded and physically interlocked cenosphere particles within the PVC matrix walls. This observation indicates a strong interaction between the filler and the matrix and also a good dispersion of cenosphere particles. By increasing the cenospheres content, the number of broken cenospheres is found to be higher, which is attributed to a shifting from ductile plastic deformation to brittle failure mechanism in the cenospheres during the foam cell formation [6].

\section{CONCLUSIONS}

PVC foam composites containing cenosphere fly ash were successfully extruded with up to $12 \mathrm{phr}$ 

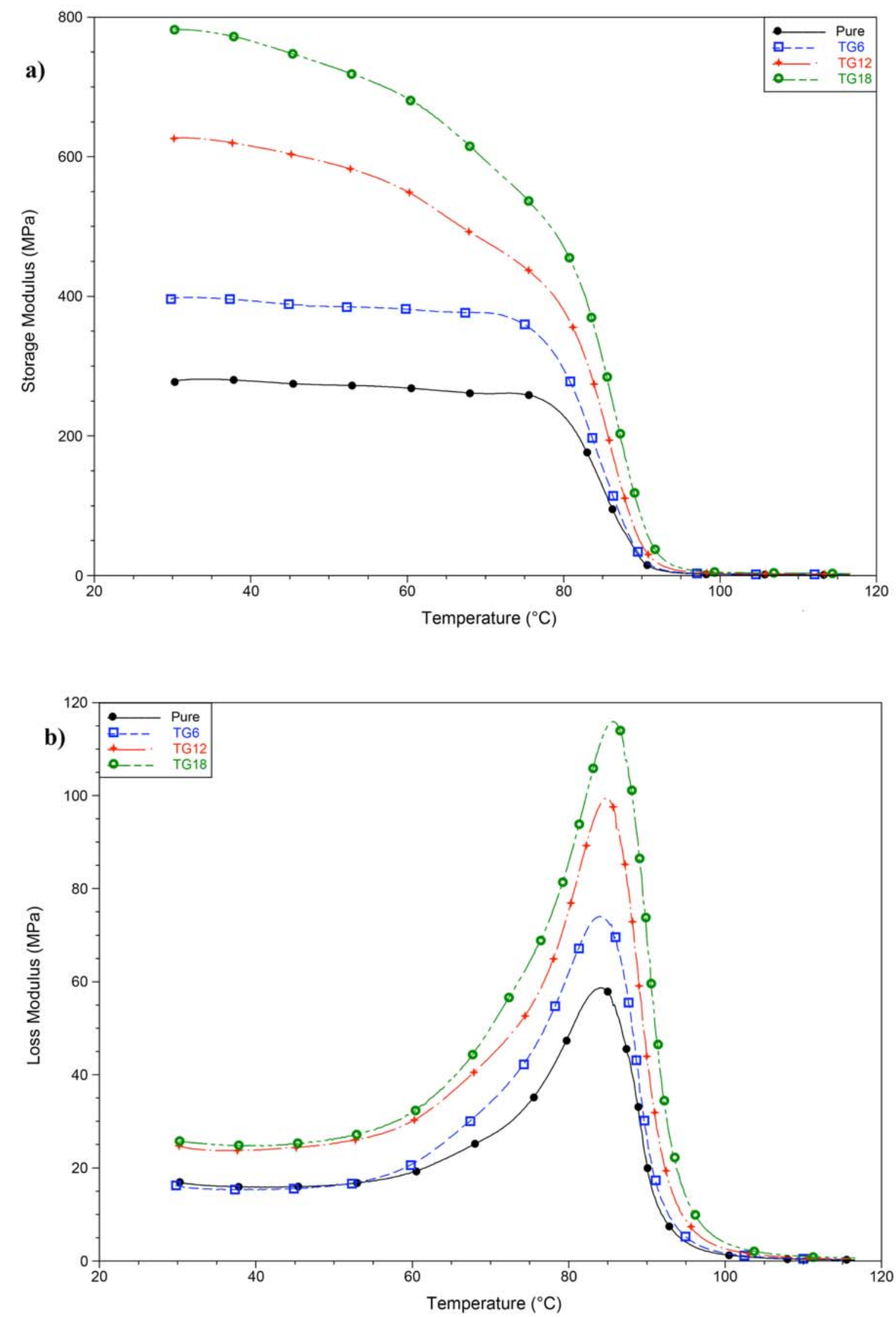

Figure 12: Dynamic mechanical analysis plots of PVC/cenosphere foam composites (a) storage modulus (E') and (b) loss modulus (E") vs. temperature. 
Table 6: Tg of PVC/Cenosphere Foam Composites as defined by the peak of Loss Modulus Curve and tan $\delta$ at $1 \mathrm{~Hz}$ Frequency

\begin{tabular}{|c|c|c|c|c|}
\hline Sample & Pure & TG6 & TG12 & TG18 \\
\hline \hline $\begin{array}{c}\mathrm{Tg}\left({ }^{\circ} \mathrm{C}\right) \\
\text { from } \mathrm{E} "\end{array}$ & 84.19 & 84.10 & 84.77 & 85.87 \\
\hline $\begin{array}{c}\mathrm{Tg}\left({ }^{\circ} \mathrm{C}\right) \\
\text { from tanס }\end{array}$ & 93.49 & 93.08 & 93.43 & 94.48 \\
\hline
\end{tabular}
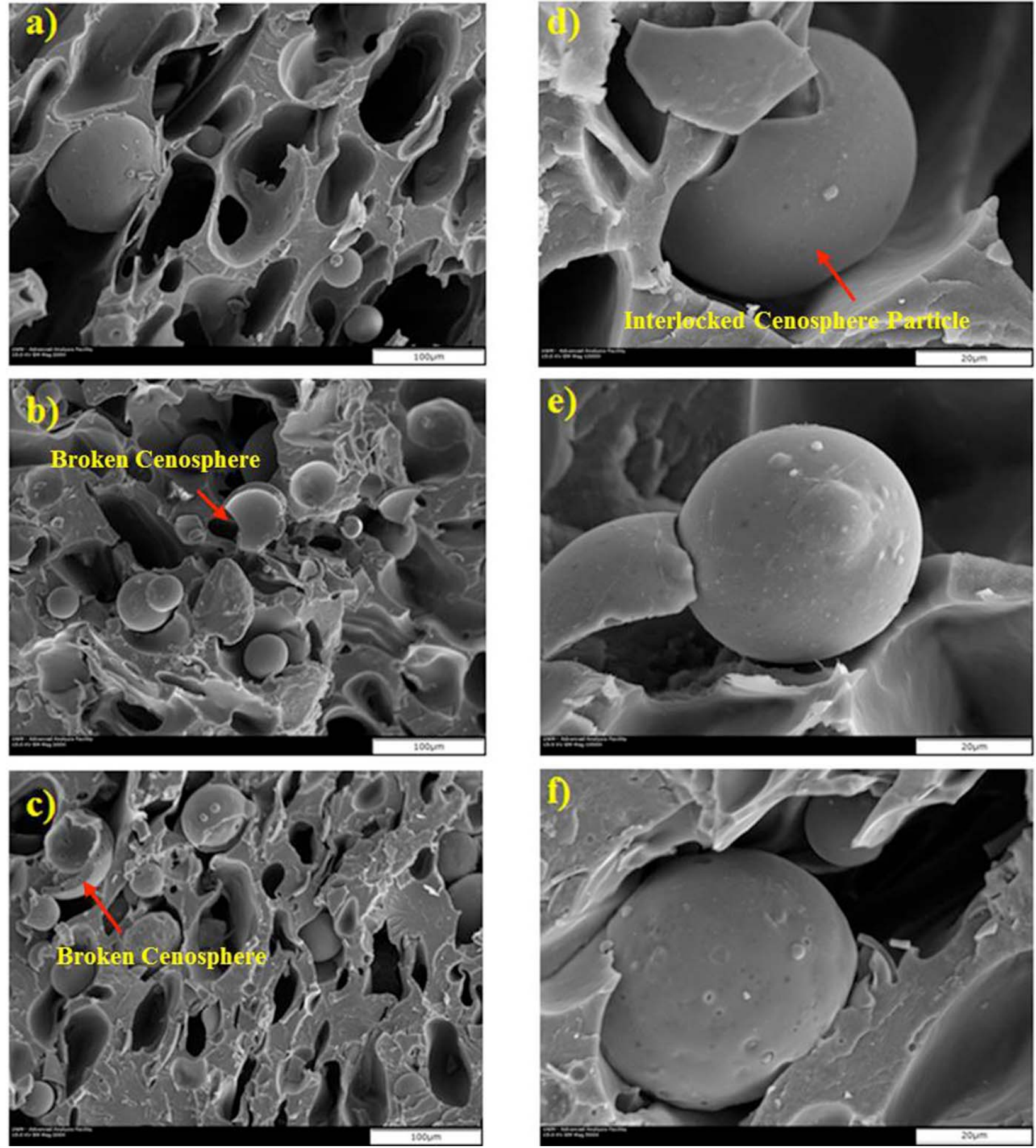

Figure 13: SEM images of PVC/Cenosphere composites, (a) TG6 (200x), (b) TG12 (200x), (c) TG18 (200x), (d) TG6 (1000x), (e) TG12 (1000x), (f) TG18 (1000x). 
loading without adversely affecting the properties of the foam. The addition of cenospheres resulted in an increase in the foam density. Both the tensile strength and modulus increased by incorporating cenosphere fly ash, indicating good interfacial bonding between the filler and the matrix. Flexural strength improved by increasing the cenospheres content, which is attributed to higher stiffness of the composites. Impact strength and impact energy remained almost constant with increasing the cenospheres content from $6 \mathrm{phr}$ to $18 \mathrm{phr}$, which indicates efficient load transfer in the composites containing cenosphere particles.

The final and primary decomposition temperatures, measured by TGA, increased and slightly decreased, respectively, whereas the enthalpy in both temperatures increased by adding more cenospheres. Dynamic mechanical analysis confirmed the increase in stiffness by increasing cenosphere content in the composites and also the presence of good interfacial adhesion between the cenosphere particles and the matrix. SEM images revealed good dispersion, distribution, and interaction between the cenosphere particles and the PVC matrix.

\section{REFERENCES}

[1] Drozhzhin VS, Danilin LD, Pikulin IV, Khovrin AN, Maximova NV, Regiushev SA, Pimenov VG. Functional materials on the basis of cenospheres, World of Coal Ash conference; Lexington, Kentucky, USA 2005. http://www.flyash.info/ 2005/47dro.pdf

[2] Matsunaga T, Kim JK, Hardcastle S, Rohatgi PK. Crystallinity and selected properties of fly ash particles. J Mat Sci Eng 2002; A325: 333-43. http://dx.doi.org/10.1016/S0921-5093(01)01466-6

[3] Sreekanth MS, Bambole VA. Effect of particle size and concentration of flyash on properties of polyester thermoplastic elastomer composites. J Miner Mat CharacEng 2009; 8(3): 237-48. http://www.scirp.org/journal/Paper Information.aspx?PaperID=20617\#.VSKV9_nF-8A

[4] Kadam P, Pawar B, Mhaske S. Studies in effect of low concentration of cenosphere on mechanical, thermal, electrical, crystallinity, colorimetric and morphological properties of epoxy cured with triethylenettramine, J Miner Mat Charac Eng 2013; 1: 117-23.

http://dx.doi.org/10.4236/jmmce.2013.14021

[5] White SC, Case ED. Characterization of fly ash from coalfired power plants. J Mat Sci 1990; 25: 5215-19. http://dx.doi.org/10.1007/BF00580153

[6] Das A, Satapathy BK. Structural, thermal, mechanical and dynamic mechanical properties of cenosphere filled polypropylene composites. J Mat Des 2011; 32: 1477-84. http://dx.doi.org/10.1016/j.matdes.2010.08.041

[7] Labella M, Zeltmann SE, Shunmugasamy VC, Gupta N, Rohatgi PK. Mechanical and thermal properties of fly ash/vinyl ester syntactic foams. J Fuel 2014; 121: 240-49. http://dx.doi.org/10.1016/..fuel.2013.12.038

[8] Senapati AK, Bhatta A, Mohanty S, Mishra PC, Routra BC. An extensive literature review on the usage of fly Ash as a reinforcing agent for different matrices. Int $\mathrm{J}$ Innov Sci Mod
Eng 2014; 2(3); 4-9. http://www.sciencedirect.com/science/ article/pii/S0261306909005561

[9] Deepthi MV, Sharma M, Sailaja RRN, Anantha $P$, Sampathkumaran P, Seetharamu S. Mechanical and thermal characteristics of high density polyethylene-fly ash cenospheres composites. J Mat Des 2010; 31: 2051-60. http://dx.doi.org/10.1016/j.matdes.2009.10.014

[10] Jena H, Pandit MK, Pradhan AK. Study the Impact Property of Laminated Bamboo-Fibre Composite Filled with Cenosphere. Int J Env Sci Develop 2012; 3(5): 456-59. http://dx.doi.org/10.7763/IJESD.2012.V3.266

[11] Qiao J, Amirkhizi AV, Schaaf K, Nemat-Nasser S. Dynamic mechanical analysis of fly ash filled polyurea elastomer. $J$ Eng Mat Tech 2011; 133: 110161-7. http://dx.doi.org/10.1115/1.4002650

[12] Wasekar PA, Kadam PG, Mhaske ST. Effect of cenosphere concentration on the mechanical, thermal, rheological and morphological properties of nylon 6, J Minerals and Materials Characterization and Engineering 2012; 11: 807-12. http://www.scirp.org/journal/jmmce/

[13] Rohatgi PK, Matsunaga T, Gupta N. Compressive and ultrasonic properties of polyester/fly ash composites. J Mat Sci 2009; 44(6): 1485-93. http://dx.doi.org/10.1007/s10853-008-3165-1

[14] Kulkarni MB, Bambole VA, Mahanwar PA. Effect of particle size of fly ash cenospheres on the properties of acrylonitrile butadiene styrene-filled composites. J Thermoplast Compos Mater 2014; 27(2): 251-67. http://dx.doi.org/10.1177/0892705712443253

[15] Manjunath BR, Sadasivamurthy P, Reddy PV, Haridas RK Studies on cenospheres as fillers for PVC compounds for applications in electrical cables. J American Institute of Chemists 2013; 86(1): 10-14. http://www.theaic.org/pub_ thechemist_journals/Vol-86-No-1/Vol-86-No1-Article-2.html

[16] Aashis SR, Saravanan S, Kishore Praveen CR, Madras G. Dielectric impedance studies of Poly(vinyl butyral)cenosphere composite films. J Polym Compos 2014; 35: 1636-43.

http://dx.doi.org/10.1002/pc.22817

[17] Thakur S, Chauhan SR. Study on mechanical and tribological behavior of cenosphere filled vinylester composites- A Taguchi method. Indian J Eng Mater Sci 2013; 20: 539-48. http://nopr.niscair.res.in/bitstream/ 123456789/25582/1/IJEMS\%2020(6)\%20539-548.pdf

[18] Chand N, Sharma P, Fahim M. Abrasive wear behavior of LDPE filled with silane treated flyash cenospheres. J Compos Interfaces 2011; 18: 575-86. http://dx.doi.org/10.1163/156855411X612267

[19] Chand N, Sharma P, Fahim M. Correlation of mechanical and tribological properties of organosilane modified cenosphere filled high density polyethylene. J Mat Sci Eng A 2010; 527: 5873-8.

http://dx.doi.org/10.1016/j.msea.2010.06.022

[20] Sharma J, Chand N, Bapat MN. Effect of cenosphere on dielectric properties of low density polyethylene. J Results Phys 2012; 2: 26-33. http://dx.doi.org/10.1016/j.rinp.2012.03.003

[21] Chauhan SR, Thakur S. Effect of micro size cenosphere particles reinforcement on tribological characteristics of vinylester composites under dry sliding conditions. J Miner Mat Charac Eng 2012; 11: 938-46. http://www.SciRP.org/ journal/jmmce

[22] Usta N. Investigation of fire behavior of rigid polyurethane foams containing fly ash and intumescent flame retardant by using a cone calorimeter. J Appl Polym Sci 2012; 124: 337282.

http://dx.doi.org/10.1002/app.35352

[23] Chow JD, Chai WL, Yeh CM, Chuang FS. Recycling and application characteristics of fly ash from municipal solid 
waste incinerator blended with polyurethane foam. J Environ Eng Sci 2008; 25(4): 461-71.

http://dx.doi.org/10.1089/ees.2006.0037

[24] Gupta N, Woldesenbetb E, Mensah P. Compression properties of syntactic foams: effect of cenosphere radius ratio and specimen aspect ratio. J Composites: Part A 2004; 35: $103-11$.

http://dx.doi.org/10.1016/j.compositesa.2003.08.001

[25] Rabinovich EB, Isner JD, SIDOR JA, Wiedl DJ. Effect of extrusion conditions on rigid PVC foam. $J$ Vin Add Tech 1997; 3(3): 210-15.

http://dx.doi.org/10.1002/vnl.10193

[26] Thomas NL. Rigid PVC foam, Formulating for sustainability. Proceedings of the blowing agent and foaming process 2004: pp. 179-89.

[27] Eaves D. Handbook of Polymer Foams. Rapra Technology Limited 2004.
[28] Khoshnoud P, Gunashekar S, Jamel MM, Abu-Zahra N. Comparative analysis of rigid PVC foam reinforced with class $\mathrm{C}$ and class F fly ash. J Miner Mat Charac Eng 2014; 2: 55465.

http://dx.doi.org/10.4236/jmmce.2014.26057

[29] Lodi PC, Souza BBD. Thermo-gravimetric analysis (TGA) after different exposures of High Density Polyethylene (HDPE) and Poly Vinyl Chloride (PVC) geomembranes. Elec J Geotech Eng 2012; 17: 3339-49. http://www.ejge.com/ 2012/Ppr12.308alr.pdf

[30] Iulianelli CGV, Maciel PMC, Tavares MIB. Preparation and characterization of PVC/Natural filler composites. J Macromolecular Symposia 2011; 299: 227-33. http://dx.doi.org/10.1002/masy.200900104

[31] Ráthy I, Kuki A, Borda J, Deák G, Zsuga M, Marossy K. Preparation and characterization of Poly(vinyl Chloride)continuous carbon fiber composites. J Appl Polym Sci 2012; 124: $190-4$.

http://dx.doi.org/10.1002/app.33617 